\title{
Review
}

\section{Reconciling the Role of Vascular Endothelial Growth Factor-Targeted Therapies in Adjuvant Renal Cell Carcinoma Treatment}

\author{
Won Kim ${ }^{\mathrm{a}, *}$, Mamta Parikh ${ }^{\mathrm{b}}$, Christopher Ryan $^{\mathrm{c}}$ and Primo Lara ${ }^{\mathrm{b}}$ \\ ${ }^{a}$ University of California, San Francisco, San Francisco, CA, USA \\ ${ }^{\mathrm{b}}$ University of California, Davis, Sacramento, CA, USA \\ ${ }^{\mathrm{c}}$ Oregon Health Sciences University, Portland, OR, USA
}

\begin{abstract}
Up to $40 \%$ of patients with high risk, localized RCC will relapse after nephrectomy and are at risk of eventually succumbing to the disease. Historically, phase 3 clinical trials failed to demonstrate meaningful benefit of adjuvant therapy in RCC, likely because these early trials used treatments that did not demonstrate meaningful clinical efficacy in mRCC. However, the clear clinical activity demonstrated by VEGF-TKIs in $\mathrm{mRCC}$ patients renewed the promise of adjuvant therapy. ASSURE, S-TRAC, and PROTECT are the first three trials to examine the clinical efficacy of 1 year of adjuvant VEGF-TKI therapy in patients with high-risk RCC following nephrectomy. In this review we reconcile the results of these studies and explore the future of adjuvant RCC therapy.
\end{abstract}

Keywords: Tyrosine kinase inhibitors, adjuvant therapy, kidney cancer

\section{INTRODUCTION}

While the survival of patients with metastatic renal cell carcinoma (RCC) has improved dramatically over the past decade due to the successful clinical development of targeted therapies and checkpoint inhibitors, advanced and metastatic RCC remains a lethal disease with significant cancer- and treatmentrelated burdens. Fortunately, just $20 \%$ of patients with RCC present with metastatic disease at the time of initial diagnosis. However, up to $40 \%$ of patients with localized or locally advanced RCC will relapse

\footnotetext{
${ }^{*}$ Correspondence to: Won Kim, MD, University of California, San Francisco, San Francisco, CA, USA. E-mail: won.kim@ucsf.edu.
}

following surgery and are at risk of succumbing to the disease [1]. Thus, there has been much effort expended to attempt to reduce the risk of relapse in patients with RCC, particularly in those with the highest risk of relapse.

Historically, multiple clinical trials failed to demonstrate clinical benefit of adjuvant therapy in RCC (Table 1). However, this was thought to be due to the fact that these early attempts at adjuvant therapy used treatments that did not demonstrate clear and measurable clinical benefit in RCC in other settings, including metastatic disease. The entry of vascular endothelial growth factor (VEGF)targeted tyrosine kinase inhibitors (TKIs) into the routine care of advanced RCC, particularly clear cell disease, renewed the promise of adjuvant therapy. 
Table 1

Selected RCC adjuvant clinical trials, prior to the VEGF-targeted TKI era

\begin{tabular}{|c|c|c|c|c|c|}
\hline & Therapy & $n$ & $\begin{array}{l}\text { Primary } \\
\text { endpoint }\end{array}$ & Results & Other results \\
\hline $\begin{array}{l}\text { Galligioni et al., Cancer } \\
1996 \text { [17] }\end{array}$ & $\begin{array}{l}\text { Autologous tumor cells and } \\
\text { BCG }\end{array}$ & $\begin{array}{l}120(1: 1 \\
\text { randomization })\end{array}$ & 5-yr DFS & $\begin{array}{l}\text { Negative: } 63 \% \text { (vs } \\
72 \% \text { for control) }\end{array}$ & 5-yr OS also negative \\
\hline $\begin{array}{l}\text { Pizzocaro et al., J Clin } \\
\text { Oncol } 2001 \text { [11] }\end{array}$ & Interferon-alfa & $247(1: 1)$ & 5-yr DFS & $\begin{array}{l}\text { Negative: } 66 \% \text { (vs } \\
66.5 \% \text { for control) }\end{array}$ & 5-yr EFS also negative \\
\hline $\begin{array}{l}\text { Messing et al., J Clin } \\
\text { Oncol } 2003 \text { [12] }\end{array}$ & Interferon-alfa & $283(1: 1)$ & OS & $\begin{array}{l}\text { Negative: } \operatorname{mOS} 5.1 \text { yrs } \\
\text { (vs } 7.4 \text { yrs for } \\
\text { control) }\end{array}$ & DFS also negative \\
\hline $\begin{array}{l}\text { Clark et al., J Clin Oncol } \\
2003 \text { [13] }\end{array}$ & Interleukin-2 & $44(1: 1)$ & 2-yr DFS & $\begin{array}{l}\text { Negative: DSMC } \\
\text { closed study early }\end{array}$ & OS also negative \\
\hline $\begin{array}{l}\text { Atzpodien, Br J Cancer } \\
2005 \text { [14] }\end{array}$ & $\begin{array}{l}\text { Interferon-alfa, interleukin-2, } \\
\text { 5-fluorouracil }\end{array}$ & $203(1: 1)$ & DFS & $\begin{array}{l}\text { Negative: mDFS } \\
2.75 \text { yrs (vs } 4.25 \text { in } \\
\text { control group) }\end{array}$ & OS also negative \\
\hline $\begin{array}{l}\text { Wood et al., Lancet } 2008 \\
\text { [18] }\end{array}$ & Autologous vaccine & $816(1: 1)$ & DFS & $\begin{array}{l}\text { Negative: HR } 0.92 \\
\quad p=0.5\end{array}$ & $\begin{array}{l}\text { OS: not mature, but } \\
\quad p=0.9\end{array}$ \\
\hline $\begin{array}{l}\text { Passalacqua et al., J } \\
\text { Immunother } 2014 \text { [15] }\end{array}$ & $\begin{array}{l}\text { Interferon-alfa and } \\
\text { interleukin-2 }\end{array}$ & $310(1: 1)$ & 5-year DFS & $\begin{array}{l}\text { Negative: } 73 \% \text { (vs } \\
73 \% \text { in the control } \\
\text { group) }\end{array}$ & 5-yr OS also negative \\
\hline $\begin{array}{l}\text { Aitchison et al., Eur J } \\
\text { Cancer } 2014 \text { [16] }\end{array}$ & $\begin{array}{l}\text { Interferon-alfa, interleukin-2, } \\
\text { and 5-fluorouracil }\end{array}$ & $309(1: 1)$ & 3-year DFS & $\begin{array}{l}\text { Negative: } 61 \% \text { (vs } \\
50 \% \text { in the control } \\
\text { group) }\end{array}$ & 5-yr OS also negative \\
\hline
\end{tabular}

The purpose of this review is to examine the data from recent adjuvant trials of VEGF-targeted TKIs and to explore the future of adjuvant therapy in RCC.

\section{RISK STRATIFICATION}

The majority of patients with localized RCC are cured with surgical resection, either radical or partial nephrectomy. Thus, surgery remains the gold standard of treatment in this patient population. The primary tumor classification (T-stage) serves as a prognostic marker of cancer-specific survival (CSS). For example, the 5-year CSS for patients with pT1 and pT2 disease are $>90 \%$ and $70 \%$, respectively. However, for patients with pT3 disease, the 5-year CSS drops dramatically to 30-50\%, and further drops to approximately $20 \%$ for patients with pT4 disease [2]. Thus, most adjuvant trials in RCC have focused on patients with at least $\mathrm{T} 2$ disease.

Another risk stratification method for nonmetastatic RCC following nephrectomy involves prognostic modelling such as the UISS scoring system [3] and the Leibovich prognosis score [4]. While these and other nomograms for nonmetastatic disease $[5,6]$ are able to risk-stratify patients into low-, intermediate-, and high-risk groups, there are subtle and important differences that should be noted. For example, the UISS score includes TNM staging, performance status, and Fuhrman grade, while the Leibovich score includes $\mathrm{T}$ stage, $\mathrm{N}$ stage, tumor size, Fuhrman grade, and tumor necrosis. UISS low-, intermediate-, and high-risk patients have 5year CSS of $91 \%, 80 \%$ and $55 \%$, respectively. Leibovich low-, intermediate-, and high-risk patients have 5-year metastasis-free survival of $97.1 \%$, $73.8 \%$, and $31.2 \%$, respectively. It is also important to note that these prognostic models were developed and validated using retrospective patient cohorts and thus subject to limitations of such methodology. Adjuvant clinical trials using these prognostic models have largely focused on patients with intermediateto high-risk disease.

Early adjuvant studies, as well as the adjuvant studies discussed in depth in this review have utilized different methods for risk stratification for clinical trial eligibility. In fact, there is no consensus on what constitutes "intermediate-risk" or "high-risk" disease, and the heterogeneity of patients enrolled in the various adjuvant RCC studies must be considered before delving into the data presented here, and any cross-study comparison must take this issue into account.

\section{EARLY ADJUVANT STUDIES}

Early adjuvant studies focused on the use of interferon alfa (IFN- $\alpha$ ), interleukin-2 (IL-2), or the combination. IFN- $\alpha$ was the standard of care for mRCC patients prior to the introduction of VEGF-targeted TKIs based on a meta-analysis of 6 prospective clinical trials [7] and served as the control arm in some early studies of VEGF TKIs. 
IL-2 received regulatory approval in 1992; however, due to the significant toxicities of therapy, treatment was reserved for younger mRCC patients with good performance status [8-10].

As summarized in Table 1, multiple attempts of using adjuvant IFN- $\alpha$ and IL-2 were met with negative results, including trials combining the two immunotherapy modalities as well as combination chemo-immunotherapy approaches [11-16]. Autologous immunotherapeutic approaches, both tumor cells and vaccines, have similarly failed [17, 18]. Additional adjuvant approaches (including radiotherapy and hormonal therapy) have also failed to demonstrate measurable clinical benefit $[19,20]$.

\section{ADJUVANT VEGF-TARGETED TKI THERAPY IN RCC: SUMMARY}

Since sorafenib became the first VEGF-targeted TKI to receive regulatory approval for the treatment of advanced RCC in 2005 [21], 5 additional TKIs have entered clinical practice, having demonstrated improved clinical outcomes in the front- and subsequent-line settings [22-26]. Given the significant impact of TKIs on the lives of patients with advanced RCC [27, 28], there was renewed hope that these TKIs may help fulfill an unmet clinical need, in the adjuvant setting for patients at the highest risk of disease relapse following nephrectomy. Here the results of the ASSURE (E2805), S-TRAC, and PROTECT studies will be briefly summarized, followed by a discussion of the 3 studies.

\section{ASSURE}

ECOG-ACRIN E2805 (ASSURE) was a phase III, double-blind, placebo-controlled trial of adjuvant sunitinib or sorafenib in patients with at least pT1b, resected RCC [29]. Notably, ASSURE, a cooperative group study which accrued patients in the US and Canada, allowed patients with non-clear cell RCC to enroll in the study. Eligible patients, stratified by recurrence risk, histology, and performance status, were randomized $1: 1: 1$ to sunitinib, sorafenib, or placebo for 54 weeks following surgery. In all, 1,943 patients were randomized between 2006 and 2010. After 1,323 patients had been randomized, the starting doses for sunitinib and sorafenib were reduced (sunitinib from $50 \mathrm{mg}$ to $37.5 \mathrm{mg}$; sorafenib from $400 \mathrm{mg}$ twice daily to $400 \mathrm{mg}$ once daily) due to high rates of treatment related therapy discontinuation. The primary endpoint was disease-free survival
(DFS); overall survival (OS) was a secondary endpoint, as were safety and quality of life measures.

Half of all enrolled patients had UISS intermediate high risk disease; the other half had UISS very high risk disease. Two-thirds of patients had AJCC stage III or IV disease. Twenty percent of enrolled patients had non-clear cell histology. After a median follow-up of 5.8 years, there was no significant difference in DFS or OS between the 3 arms. Median DFS for sunitinib was 5.8 years (HR 1.02, $p=0.80$ ), 6.1 years for sorafenib (HR $0.97, p=0.72$ ), and 6.6 years for placebo. Median OS was not reached in any group: 5-year OS was $77.9 \%, 80.5 \%$, and $80.3 \%$ for the sunitinib, sorafenib, and placebo groups, respectively (HR 1.17 and $p=0.18$ for sunitinib, HR 0.98 and $p=0.86$ for sorafenib).

Treatment-related toxicity may have had an impact on the study results. By cycle 3, less than half (42\% in the sunitinib group and $31 \%$ in the sorafenib group) were taking the intended dose of drug due to dose reductions. Prior to the mid-study change in dosing, $44 \%$ of patients taking sunitinib and $45 \%$ taking sorafenib discontinued therapy altogether. Even after the dose reduction, $34 \%$ of patients in the sunitinib group and $30 \%$ of patients in the sorafenib group discontinued study therapy. The most common treatment-related grade $\geq 3$ adverse events included hand-foot syndrome (15\% and $33 \%$ in the sunitinib and sorafenib groups, respectively, vs $1 \%$ in the placebo group), hypertension (17\% and $16 \%$ in the sunitinib and sorafenib groups, respectively, vs $4 \%$ in placebo), and diarrhea (10\% and $9 \%$ in the sunitinib and sorafenib groups, respectively, vs $<1 \%$ in placebo).

Due to the lack of efficacy and significant toxicities associated with VEGF-targeted TKIs in this study, the authors concluded that there is no role for adjuvant TKI therapy in intermediate to high risk kidney cancer.

\section{S-TRAC}

S-TRAC was a phase III, double-blind, placebocontrolled study of adjuvant sunitinib versus placebo for one year (54 weeks) in patients with completely resected RCC [30]. Like S-TRAC, eligible patients were stratified by performance status and recurrence risk. Unlike ASSURE, S-TRAC excluded patients with non-clear cell RCC, and it was a global study, accruing patients in 99 countries. Furthermore, in contrast to ASSURE, only a single dose reduction of sunitinib dosing (to $37.5 \mathrm{mg}$ ) was permitted for 
toxicity. S-TRAC enrolled 615 patients, randomized 1:1 to sunitinib versus placebo, between 2007 and 2011. The primary endpoint was DFS; OS was a secondary endpoint.

S-TRAC used modified UISS criteria, and enrolled patients with one of three risk groups. Group A patients (approximately $91 \%$ of those enrolled) had stage 3 tumors; the remainder had either stage 4 tumor (Group B, 1.3\%) or loco-regional nodal involvement (Group C, 8\%). After a median follow-up of 5.4 years, the median DFS was 6.8 years in the sunitinib group, and 5.6 years in the placebo group (HR $0.76, p=0.03$ ). At 5 years, the proportion of patients who were disease free were $59.3 \%$ and $51.3 \%$ in the sunitinib and placebo groups, respectively. OS data was not mature at the time of data cutoff. Median OS was not reached in either group, and the HR was 1.01 $(p=0.94)$.

Nearly two-thirds (63.4\%) of sunitinib-treated patients experienced Grade $\geq 3$ adverse events (compared to $21.7 \%$ in the placebo group); $34 \%$ of patients who received sunitinib had dose reductions, compared to $2 \%$ in the placebo group. Fifty-five percent of patients randomized to sunitinib completed the full treatment, with $28 \%$ discontinuing therapy due to AEs.

Based on the results of this study, sunitinib received FDA approval for "the adjuvant treatment of adult patients at high risk of recurrent renal cell carcinoma following nephrectomy" in late 2017.

\section{PROTECT}

PROTECT was a phase III, double-blind, placebocontrolled study of adjuvant pazopanib versus placebo for 1 year for patients with resected clear cell RCC [31]. Eligible patients had high grade (Fuhrman grades 3 or 4) pT2N0, any pT3-T4N0 disease, or any $\mathrm{pTxN} 1$ disease. Eligible patients were randomized 1:1, stratified by nephrectomy type and TNM stage. Like ASSURE, the study was designed with pazopanib at the maximum daily dose $(800 \mathrm{mg}$ once daily); however, due to treatment discontinuation, the dose was reduced to $600 \mathrm{mg}$ once daily, with the option to escalate dosing after 8-12 weeks of therapy. Between 2010 and 2013, 1538 patients were enrolled; 403 patients were randomized while the starting dose of pazopanib was $800 \mathrm{mg}$ once daily (ITT $_{800}$ cohort); 1135 patients were randomized after the starting dose of pazopanib was reduced to $600 \mathrm{mg}$ once daily (ITT 600 cohort). The primary endpoint of the study was DFS for the ITT $_{600}$ cohort, with OS and DFS in the ITT $_{800}$ cohort and in all randomized patients $\left(\mathrm{ITT}_{\text {all }}\right)$ as secondary endpoints.

The majority of patients enrolled into PROTECT had pT2N0 disease (77-79\% across drug and dosing cohorts); less than $10 \%$ of patients had $\mathrm{T} 4$ or N1 disease, and approximately $14 \%$ of patients had high grade pT2 disease. After a median follow-up of approximately 30 months, the $\mathrm{ITT}_{600}$ cohort did not meet the primary endpoint (HR $0.86, p=0.16$ ). After a median follow-up of 48 months, there was a significant benefit in DFS in the ITT $_{800}$ cohort (HR $0.68, p=0.02)$ and ITT $_{\text {all cohort }}$ (HR $0.80, p=0.01$ ). OS analyses did not demonstrate significant benefit in favor of pazopanib in any of the $\mathrm{ITT}_{600}, \mathrm{ITT}_{800}$, or ITT $_{\text {all }}$ cohorts.

In both the ITT $_{600}$ and ITT $_{800}$ groups, approximately half $(49 \%)$ of patients completed 12 months of therapy. $51 \%$ and $60 \%$ of patients in the ITT $_{600}$ and ITT $_{800}$ cohorts, respectively, required dose reduction of pazopanib. Thirty-five and 39\% of patients in the $\mathrm{ITT}_{600}$ and $\mathrm{ITT}_{800}$ cohorts, respectively, required treatment discontinuation due to treatment-related toxicities. Twenty-one percent of patients in the ITT $_{600}$ cohort were able to tolerate a protocol-defined dose escalation to the full $800 \mathrm{mg}$ dose of pazopanib.

\section{DISCUSSION: RECONCILING ASSURE, S-TRAC, AND PROTECT}

Table 2 summarizes the key similarities and differences in study characteristics and outcomes of ASSURE, S-TRAC, and PROTECT. While it may be tempting to group these three studies together as adjuvant trials of VEGF-TKIs, there are many critical differences that must be noted in order to be able to reconcile the results of these studies.

\section{Dosing}

In the original study design for ASSURE, the starting dose for sunitinib was $50 \mathrm{mg}$ daily (given on a 4-weeks-on, 2-weeks-off schedule) and sorafenib $400 \mathrm{mg}$ twice daily, per the manufacturer's label for metastatic disease. Due to high rates of treatment discontinuation due to adverse events, after approximately 1300 patients were already enrolled, doses of both drugs were reduced (sunitinib to $37.5 \mathrm{mg}$ daily given on the same $4 / 2$ schedule, sorafenib to $400 \mathrm{mg}$ once daily), with a single dose reduction (sunitinib down to $25 \mathrm{mg} \mathrm{4/2}$, sorafenib to $200 \mathrm{mg}$ once daily) allowed. Similarly, the starting dose of pazopanib in PROTECT was reduced from $800 \mathrm{mg}$ once daily to 
Table 2

Comparison of ASSURE, S-TRAC, and PROTECT

\begin{tabular}{|c|c|c|c|}
\hline & ASSURE [29] & S-TRAC [30] & PROTECT [31] \\
\hline Accrual between & $2006-2010$ & $2007-2011$ & 2010-2013 \\
\hline Accrual location & US/Canada & International & International \\
\hline Sponsor & ECOG/ACRIN & Pfizer & Novartis/GSK \\
\hline \# of patients & 1943 & 615 & 1538 \\
\hline Primary endpoint & DFS (OS 2nd) & DFS (OS 2nd) & $\begin{array}{l}\mathrm{DFS}_{\text {in }} \mathrm{ITT}_{600}\left(\mathrm{DFS} \text { in } \mathrm{ITT}_{800} \text {, }\right. \\
\left.\mathrm{ITT}_{\text {all }} \text {, and OS } 2 \mathrm{nd}\right)\end{array}$ \\
\hline Non-clear cell allowed? & $\mathrm{Y}(21 \%)$ & $\mathrm{N}$ & $\mathrm{N}$ \\
\hline Eligibility & $\begin{array}{l}\text { pT1b N0 M0 (FG3-4) } \\
\text { pT2-T4 N0 M0 (FG any) } \\
\text { pTany N+ M0 (FG any) }\end{array}$ & $\begin{array}{l}\text { pT3-T4, N0 M0 (FG any) } \\
\text { pTany N+ M0 (FG any) }\end{array}$ & $\begin{array}{l}\text { pT2 N0 M0 (FG 3-4) } \\
\text { pT3-T4 N0 M0 (FG any) } \\
\text { pTany N0 M0 (FG any) }\end{array}$ \\
\hline Drug (and dosing) & $\begin{array}{l}\text { SUN } 50 \mathrm{mg}(4 / 2) \\
\text { SOR } 400 \mathrm{mg} \text { BID } \\
\text { After } 68 \% \text { were enrolled: } \\
\text { SUN reduced to } 37.5 \mathrm{mg} \\
\text { SOR reduced to once daily }\end{array}$ & SUN $50 \mathrm{mg}(4 / 2)$ & $\begin{array}{l}\text { PAZ } 800 \mathrm{mg} \text { daily } \\
\text { After } 26 \% \text { were enrolled: } \\
\text { PAZ reduced to } 600 \mathrm{mg}\end{array}$ \\
\hline $\begin{array}{l}\text { Drug discontinuation due to } \\
\text { AEs (vs placebo) }\end{array}$ & $\begin{array}{l}\text { SUN 50: } 44 \%(\text { vs } 11 \%) \\
\text { SUN } 37.5: 34 \%(\text { vs } 10 \%) \\
\text { SOR } 400 \times 2: 45 \%(\text { vs } 11 \%) \\
\text { SOR } 400 \times 1: 30 \%(\text { vs } 10 \%)\end{array}$ & $28 \%($ vs $6 \%)$ & $\begin{array}{l}\text { PAZ 800: } 39 \% \text { (vs } 6 \% \text { ) } \\
\quad \text { PAZ 600: } 35 \% \text { (vs } 5 \% \text { ) }\end{array}$ \\
\hline $\begin{array}{l}\text { Radiographic assessment for } \\
\text { primary endpoint }\end{array}$ & Investigator & Central (independent) & Investigator \\
\hline Median followup, yrs & 5.8 & 5.4 & $\begin{array}{l}2.6 \text { (for primary endpoint) } \\
4.0 \text { (for } \text { ITT }_{800} \text { cohort) }\end{array}$ \\
\hline mDFS, placebo, yrs & 6.6 & $\stackrel{5.6}{\# 4.5 \text {, investigator review }}$ & $\begin{array}{l}\mathrm{NR} \text { (for } \mathrm{ITT}_{600} \text { analysis) } \\
4.5 \text { (for } \mathrm{ITT}_{800} \text { analysis) }\end{array}$ \\
\hline mDFS, treatment, yrs (HR) & $\begin{array}{l}\text { SUN: } 5.8(\text { HR } 1.02, p=0.8) \\
\text { SOR: } 6.1(\text { HR } 0.97, p=0.72) \\
\text { *similar results in clear cell } \\
\text { cohort }\end{array}$ & $\begin{array}{l}6.8(\text { HR } 0.76, p=0.03) \\
\quad \text { 6 } 6.5, \text { investigator review } \\
(\text { HR } 0.81, p=0.08)\end{array}$ & $\begin{array}{l}\text { NR } \\
\text { ITT }_{600}: \text { HR } 0.86(p=0.16) \\
\text { ITT }_{800}: \text { HR } 0.69(p=0.02) \\
\text { ITT }_{\text {all }}: \text { HR } 0.80(p=0.01)\end{array}$ \\
\hline OS & $\begin{array}{l}5 \text { yr OS: } \\
\text { Placebo: } 80.3 \% \\
\text { SUN: } 77.9 \% \text { (HR 1.17) } \\
\text { SOR: } 80.5 \% \text { (HR 0.98) }\end{array}$ & HR 1.014 & $\begin{array}{l}\text { ITT }_{600}: \operatorname{HR} 0.79(p=0.16) \\
\text { ITT }_{800}: \text { HR } 0.89(p=0.65) \\
\text { ITT }_{\text {all }}: \text { HR } 0.82(p=0.15)\end{array}$ \\
\hline
\end{tabular}

$600 \mathrm{mg}$ once daily (with dose reduction to $400 \mathrm{mg}$ once daily allowed); in PROTECT, the primary endpoint of the study was changed to analyze the DFS in this reduced dose cohort. The $\mathrm{ITT}_{800}$ cohort $(\sim 25 \%$ of enrolled patients), despite the fact that less than half of the patients assigned to pazopanib completed 12 months of therapy, did demonstrate a DFS benefit, suggesting that the higher dose may be necessary to demonstrate a clinical benefit of adjuvant TKI therapy.

Patients randomized to sunitinib on S-TRAC were treated with the full dose, with a single dose reduction to $37.5 \mathrm{mg}$ daily on a $4 / 2$ schedule allowed; S-TRAC is the only one of the 3 studies that did not change the starting dose of the TKI. Interestingly, S-TRAC also had the lowest treatment-related discontinuation rate: numerically, the treatment-related discontinuation rate was lower in S-TRAC compared to reduced-dose cohorts in the ASSURE and
PROTECT studies. More patients completed the 1year duration of adjuvant therapy on S-TRAC (56\%) than the ASSURE and PROTECT studies (both less than 50\%). Along with the results of the ITT $_{800}$ cohort in the PROTECT study, these results suggest that treatment intensity and duration may play a role in the clinical benefit of adjuvant therapy (at least for the DFS endpoint).

\section{Patient characteristics}

ASSURE stands out from this group of trials for including patients with non-clear cell RCC ( $21 \%$ of the patient population). It is unclear how this may have impacted the final results of the study. However, given that real world data suggests that patients with advanced non-clear cell RCC have worse prognosis and derive less clinical benefit from VEGF TKIs compared to their clear cell counterparts [32], it may be 
reasonable to suspect that this may have contributed to a negative result in ASSURE. Furthermore, there are other significant differences in the patient characteristics of the three studies.

The ASSURE study also had the broadest risk profile of the three studies, including patients with pT1b disease (Fuhrman grade 3-4). PROTECT allowed patients with at least pT2 (or any T provided they had $\mathrm{N}+$ disease), and S-TRAC allowed patients with at least pT3 (or any $\mathrm{T}$ provided they had $\mathrm{N}+$ disease). In all, approximately one-third of ASSURE patients had AJCC stage I/II disease, while PROTECT included half as many and S-TRAC did not include any such patients. These differences are reflected in the longer mDFS of the placebo group in ASSURE compared to the other studies. The differences in patient populations enrolled also make it more difficult to compare the results of the three studies head-to-head, although the data may suggest that patients at the highest risk of relapse may be the more likely to benefit from adjuvant therapy (i.e. lower risk patients are more likely to be cured, and thus less likely to benefit from systemic therapy).

\section{Other study characteristics}

As discussed above, the studies are more notable for their differences than similarities. For example, ASSURE was a cooperative group study that accrued patients in US and Canada, while PROTECT and STRAC were industry-sponsored phase III studies that accrued patients internationally. Another clear example can be observed in treatment discontinuation rates among studies: $44 \%$ of patients assigned to sunitinib in ASSURE discontinued therapy due to treatmentrelated toxicities, while only $28 \%$ of patients assigned to sunitinib in S-TRAC did the same, and $39 \%$ in the pazopanib-treated patients in PROTECT. It is unlikely that the etiologies of this discrepancy will ever be revealed.

Another notable difference was the approach in assessing the primary endpoint in the three studies: DFS was assessed by the investigator in ASSURE and PROTECT, while it was assessed by blinded, central, independent review in S-TRAC. It could be argued that investigator-based assessment may lead to an inherent bias. In fact, by investigator-assessment of DFS in S-TRAC, mDFS in both sunitinib-treated and placebo groups were shorter, and the improvement in DFS demonstrated by sunitinib was no longer statistically significant $(p=0.08)$.

\section{DISCUSSION: FUTURE OF ADJUVANT THERAPY}

Unfortunately, no clear recommendation for adjuvant VEGF-targeted TKI therapy emerges from the results of these three studies. While S-TRAC (and the ITT $_{800}$ cohort of PROTECT) does suggest potential benefit of full-dose TKI therapy in patients at the highest risk of disease relapse, physicians cannot ignore the fact that ASSURE and PROTECT, two much larger studies, were negative for the primary endpoint of DFS. Patients at low risk for disease relapse should not receive adjuvant TKI therapy enrollment in a clinical trial or surveillance remains the standard of care. Patients at high risk for recurrent disease should be informed that adjuvant sunitinib has received regulatory approval and is an option. However, there should be an informed discussion regarding the potential benefits and risks of adjuvant TKI therapy, including the fact that enrollment in a clinical trial or surveillance are viable options, as well.

Additionally, a question that all health care providers should ask: is DFS an adequate endpoint for an adjuvant study? The question becomes even more relevant here given the treatment "burden" of TKI therapy, reflected in the rates of significant toxicities, decline in quality of life measures, and treatment discontinuation seen in these clinical trials (in a select, and more fit, clinical trials population). None of the studies have demonstrated any suggestion of an OS benefit, although the median follow-up at the time the data were analyzed may have been too short for sufficient events.

Results of additional phase III adjuvant targeted therapies are pending (Table 3). SORCE is a study of placebo vs 1 or 3 years of adjuvant sorafenib that is being conducted in the United Kingdom. ATLAS randomizes high risk patients to 3 years of adjuvant axitinib or placebo. EVEREST (S0931) is a cooperative group study that randomized patients to 1 year or everolimus or placebo. All studies have finished accrual and results are pending. However, given the differences in these studies, already discussed above for ASSURE, S-TRAC, and PROTECT, it is unclear if these studies will add any clarity beyond what we already know.

Checkpoint inhibitors have now entered the treatment landscape of advanced RCC. Nivolumab monotherapy demonstrated a clear survival benefit in patients with treatment-refractory clear cell RCC, and received regulatory approval in 2015 [33]. Recently 
Table 3

Ongoing adjuvant therapy trials in renal cell carcinoma

\begin{tabular}{|c|c|c|}
\hline Study & Drugs & Study characteristics \\
\hline SORCE (MRC) NCT00492258 & Sorafenib (1 yr vs 3 yrs) & Phase III; UK; Leibovich >3; any histology; $\mathrm{n}$ \\
\hline ATLAS NCT01599754 & Axitinib (3 yrs) & Phase III; Global; >pT2 or any N1; clear cell only \\
\hline EVEREST (S0931) NCT01120249 & Everolimus ( 1 yr) & $\begin{array}{l}\text { Phase III; US; intermediate-high or very high risk } \\
\text { disease; any histology }\end{array}$ \\
\hline IMmotion010 NCT03024996 & Atezolizumab (1 yr) & $\begin{array}{l}\text { Phase III; Global; high risk per Leibovich, allows } \\
\text { patients with M1 with complete resection; clear cell } \\
\text { or sarcomatoid }\end{array}$ \\
\hline PROSPER (E8143) NCT03055013 & $\begin{array}{l}\text { Nivolumab (perioperative; } \\
\text { pre- and post-nephrectomy) }\end{array}$ & Phase III; US; >pT2 or any N+; any histology \\
\hline KEYNOTE-564 NCT03142334 & Pembrolizumab $(1 \mathrm{yr})$ & $\begin{array}{l}\text { Phase III; Global; pT2 (FG4 or sarcomatoid), >pT3, any } \\
\text { N+, M1 with complete resection; clear cell only }\end{array}$ \\
\hline
\end{tabular}

the results of CheckMate 214, a randomized phase III study of nivolumab plus ipilimumab vs sunitinib, demonstrated a survival benefit in favor of the immunotherapy combination in patients with intermediate to high risk clear cell RCC [34]. IMmotion 151, a randomized phase III study of atezolizumab and bevacizumab vs sunitinib, met its primary endpoint of PFS in favor of the combination therapy in PD-L1+ patients [35]. Given the promising efficacy, as well as potentially lower toxicity rates of PD-1/PD-L1 inhibitors (particularly in the monotherapy setting), multiple adjuvant checkpoint inhibitor therapies are now accruing patients (Table 3 ) and results are eagerly anticipated. It is important to note that in all of the these studies the primary endpoint is DFS, with OS being analyzed as a secondary endpoint.

Finally, the clearest shortcoming in adjuvant therapy is the lack of biomarkers. While $20-40 \%$ of patients with RCC may experience relapsed disease after nephrectomy, we do not know which 20-40\%. More importantly, we do not know how to select patients who are most likely to reap the benefit of adjuvant therapy to make the burden of potential treatment toxicities tolerable to patients and their physicians. The fact is that the three studies discussed in this review have randomized over 4000 patients to answer the question of whether there is a role for adjuvant TKI therapy in RCC patients, and yet there is no clear answer. Another 2500 patients have been randomized in SORCE and ATLAS; another 1500 in EVEREST. Another 2400 patients will be randomized in the currently accruing adjuvant checkpoint inhibitor studies. This is after thousands of patients have already been randomized in the previous generation of adjuvant studies in RCC, without a single treatment that has led to meaningful clinical benefit for patients in the adjuvant setting. The rich correlatives that are part of ongoing studies promise better insight into patient selection - the immense and unmet clinical needs of patients demand it.

\section{CONCLUSIONS}

ASSURE, S-TRAC, and PROTECT are the first three studies to report on the efficacy of VEGFtargeted TKIs as adjuvant therapy in renal cell carcinoma. The studies have reported mixed results, with ASSURE and PROTECT both reporting negative results on the primary analyses of DFS and secondary analyses of OS, and S-TRAC demonstrating improved DFS in favor of adjuvant sunitinib in patients with UISS-high risk disease. Differences in study design, including patient eligibility (including risk assessment), dosing regimens, and DFS assessments make for difficult cross-study comparisons. The data suggest that there may be a role for fulldose adjuvant TKI therapy patients with completely resected clear cell RCC at the highest risk for disease relapse. However, when the results are taken in full, routine use of adjuvant TKI therapy cannot be considered standard of care at this time; patient selection is critical, as well as careful counseling regarding the potential risks and benefits of adjuvant TKI therapy. The lack of biomarkers for patient selection is a critical unmet need, and there must be greater urgency to develop predictive biomarkers as additional therapeutic modalities, including checkpoint inhibitors, are entering into clinical trials.

\section{REFERENCES}

[1] Siegel RL, Miller KD, Jemal A. Cancer statistics, 2016. CA Cancer J Clin. 2016;66(1):7-30.

[2] Frank I, et al. Independent validation of the 2002 American Joint Committee on cancer primary tumor classification for renal cell carcinoma using a large, single institution cohort. J Urol. 2005;173(6):1889-92. 
[3] Zisman A, et al. Risk group assessment and clinical outcome algorithm to predict the natural history of patients with surgically resected renal cell carcinoma. J Clin Oncol. 2002;20(23):4559-66.

[4] Leibovich BC, et al. Prediction of progression after radical nephrectomy for patients with clear cell renal cell carcinoma: A stratification tool for prospective clinical trials. Cancer. 2003;97(7):1663-71.

[5] Kattan MW, et al. A postoperative prognostic nomogram for renal cell carcinoma. J Urol. 2001;166(1):63-7.

[6] Sorbellini M, et al. A postoperative prognostic nomogram predicting recurrence for patients with conventional clear cell renal cell carcinoma. J Urol. 2005;173(1):48-51.

[7] Motzer RJ, et al. Interferon-alfa as a comparative treatment for clinical trials of new therapies against advanced renal cell carcinoma. J Clin Oncol. 2002;20(1): 289-96.

[8] McDermott DF, et al. Randomized phase III trial of highdose interleukin-2 versus subcutaneous interleukin-2 and interferon in patients with metastatic renal cell carcinoma. J Clin Oncol. 2005;23(1):133-41.

[9] Yang JC, et al. Randomized study of high-dose and lowdose interleukin-2 in patients with metastatic renal cancer. J Clin Oncol. 2003;21(16):3127-32.

[10] Fyfe GA, et al. Long-term response data for 255 patients with metastatic renal cell carcinoma treated with highdose recombinant interleukin-2 therapy. J Clin Oncol. 1996;14(8):2410-1.

[11] Pizzocaro G, et al. Interferon adjuvant to radical nephrectomy in Robson stages II and III renal cell carcinoma: A multicentric randomized study. J Clin Oncol. 2001;19(2):425-31.

[12] Messing EM, et al. Phase III study of interferon alfa-NL as adjuvant treatment for resectable renal cell carcinoma: An Eastern Cooperative Oncology Group/Intergroup trial. J Clin Oncol. 2003;21(7):1214-22.

[13] Clark JI, et al. Adjuvant high-dose bolus interleukin2 for patients with high-risk renal cell carcinoma: A cytokine working group randomized trial. J Clin Oncol. 2003;21(16):3133-40.

[14] Atzpodien J, et al. Adjuvant treatment with interleukin2- and interferon-alpha2a-based chemoimmunotherapy in renal cell carcinoma post tumour nephrectomy: Results of a prospectively randomised trial of the German Cooperative Renal Carcinoma Chemoimmunotherapy Group (DGCIN). Br J Cancer. 2005;92(5):843-6.

[15] Passalacqua R, et al. Adjuvant low-dose interleukin-2 (IL-2) plus interferon-alpha (IFN-alpha) in operable renal cell carcinoma (RCC): A phase III, randomized, multicentre trial of the Italian Oncology Group for Clinical Research (GOIRC). J Immunother. 2014;37(9):440-7.

[16] Aitchison M, et al. Adjuvant 5-flurouracil, alpha-interferon and interleukin- 2 versus observation in patients at high risk of recurrence after nephrectomy for renal cell carcinoma: Results of a phase III randomised European Organisation for Research and Treatment of Cancer (Genito-Urinary Cancers Group)/National Cancer Research Institute trial. Eur J Cancer. 2014;50(1):70-7.

[17] Galligioni E, et al. Adjuvant immunotherapy treatment of renal carcinoma patients with autologous tumor cells and bacillus Calmette-Guerin: Five-year results of a prospective randomized study. Cancer. 1996;77(12):2560-6.

[18] Wood C, et al. An adjuvant autologous therapeutic vaccine (HSPPC-96; vitespen) versus observation alone for patients at high risk of recurrence after nephrectomy for renal cell carcinoma: A multicentre, open-label, randomised phase III trial. Lancet. 2008;372(9633):145-54.

[19] Pizzocaro G, et al. Adjuvant medroxyprogesterone acetate and steroid hormone receptors in category M0 renal cell carcinoma. An interim report of a prospective randomized study. J Urol. 1986;135(1):18-21.

[20] Kjaer M, et al. A randomized trial of postoperative radiotherapy versus observation in stage II and III renal adenocarcinoma. A study by the Copenhagen Renal Cancer Study Group. Scand J Urol Nephrol. 1987;21(4):285-9.

[21] Escudier B, et al. Sorafenib in advanced clear-cell renal-cell carcinoma. N Engl J Med. 2007;356(2):125-34.

[22] Motzer RJ, et al. Sunitinib versus interferon alfa in metastatic renal-cell carcinoma. N Engl J Med. 2007; 356(2):115-24.

[23] Sternberg CN, et al. Pazopanib in locally advanced or metastatic renal cell carcinoma: Results of a randomized phase III trial. J Clin Oncol. 2010;28(6):1061-8.

[24] Rini BI, et al. Comparative effectiveness of axitinib versus sorafenib in advanced renal cell carcinoma (AXIS): A randomised phase 3 trial. Lancet. 2011;378(9807): 1931-9.

[25] Choueiri TK, et al. Cabozantinib versus Everolimus in Advanced Renal-Cell Carcinoma. N Engl J Med. 2015;373(19):1814-23.

[26] Motzer RJ, et al. Lenvatinib, everolimus, and the combination in patients with metastatic renal cell carcinoma: A randomised, phase 2, open-label, multicentre trial. Lancet Oncol. 2015;16(15):1473-82.

[27] Motzer RJ, et al. Survival and prognostic stratification of 670 patients with advanced renal cell carcinoma. J Clin Oncol. 1999; 17(8):2530-40.

[28] Heng DY, et al. Prognostic factors for overall survival in patients with metastatic renal cell carcinoma treated with vascular endothelial growth factor-targeted agents: Results from a large, multicenter study. J Clin Oncol. 2009;27(34): 5794-9.

[29] Haas NB, et al. Adjuvant sunitinib or sorafenib for highrisk, non-metastatic renal-cell carcinoma (ECOG-ACRIN E2805): A double-blind, placebo-controlled, randomised, phase 3 trial. Lancet. 2016;387(10032):2008-16.

[30] Ravaud A, et al. Adjuvant sunitinib in high-risk renal-cell carcinoma after nephrectomy. N Engl J Med. 2016;375(23): 2246-54.

[31] Motzer RJ, et al. Randomized phase III trial of adjuvant pazopanib versus placebo after nephrectomy in patients with localized or locally advanced renal cell carcinoma. J Clin Oncol. 2017:JCO2017735324.

[32] Kroeger N, et al. Metastatic non-clear cell renal cell carcinoma treated with targeted therapy agents: Characterization of survival outcome and application of the International mRCC Database Consortium criteria. Cancer. 2013;119(16):2999-3006.

[33] Motzer RJ, et al. Nivolumab versus everolimus in advanced renal-cell carcinoma. N Engl J Med. 2015;373(19): 1803-13.

[34] Escudier B, et al. CheckMate 214: Efficacy and Safety of Nivolumab Plus Ipilimumab vs Sunitinib for TreatmentNaive Advanced or Metastatic Renal Cell Carcinoma, Including IMDC Risk and PD-L1 Expression Subgroups. Presented at ESMO Congress, Madrid. 2017.

[35] Motzer R, et al. IMMotion151: A randomized phase III study of atezolizumab plus bevacizumab vs sunitinib in untreated metastatic renal cell carcinoma (mRCC). J Clin Oncol. 2018;36:(suppl 6S; abstr 578). 